\title{
Femoral Osteosynthesis in Black Capuchin Monkey (Sapajus nigritus) using Locking Plate
}

\author{
Guilherme Henrique Fernandes Barranco', Maria Stella Fernandes Villela ${ }^{2}$, \\ Gracila Heitor de Oliveira ${ }^{3}$, Stephanie Fernandez ${ }^{4}$, Nathália Gonçalves de Santana ${ }^{4}$, \\ Tatiana Morosini de Andrade Cruvinel ${ }^{4} \&$ Victor José Vieira Rossetto ${ }^{4}$
}

\begin{abstract}
Background: Locking bone plates for internal fixation are characterized by plates with a locknut by screwing in a threaded chamber. The increased stability associated with less vascular lesion contribute to the lower risk of complications and makes the locking bone plates especially interesting in fracture management of wild animals to be reintroduced into nature. The aim of this report is to describe the case of a black capuchin monkey with a femoral fracture, submitted to internal fixation using locking plate, with a satisfactory postoperative evolution, characterized by the bone consolidation and full recovery of the function of the member.

Case: An exemplar of an adult male black capuchin monkey (Sapajus nigritus) with $4.2 \mathrm{~kg}$ of body weight was presented due to a comminuted, diaphyseal fracture of the left femur. The animal was then submitted to internal fixation of the femoral fracture using a $2.0 \mathrm{~mm}$ locking plate with 11 holes. For the internal fixation, the plate was contoured and positioned on the lateral surface of the bone. In addition, four locking screws were inserted through both cortices in the proximal bone segment, while other three locking screws were inserted in the distal bone segment. Two of the distal locking screws were inserted through both bone cortices, while one of them were inserted through only one bone cortical. The animal showed complete functional recovery of the left hind limb at 30 days postoperatively. Despite this, it was visualized at the radiographic examination a partial release of the plate from the distal bone segment. Due to this, the animal was submitted to another surgical intervention to replace the distal locking screws by bicortical locking screws. The animal showed hind limb weight support at the second day postoperatively. The complete functional recovery of the left hind limb, however, was verified at 26 days postoperatively. In this moment, it was performed a new radiographic examination, which allowed the visualization of bone consolidation, and the animal was reintroduced into its natural habitat.

Discussion: The choice of the bone plate may play a fundamental role in the bone healing process. Among many bone plates configuration, locking plates are highlighted, as they offer greater angular stability to the fracture and result in less injuring periosteum and blood vessels. In addition, other methods for internal fixation are related to numerous postoperative complications. Despite the low rate of complications of the locking system, in the present case, it was visualized the partial release of the plate from the distal bone segment, which is probably related to the higher concentration of load near the sniffle joint, and the early release of one monocortical screw. The use of monocortical screws is permissible when properly locked in the threaded chambers of the plate. In the present case, however, it is believed that the early release of the distal monocortical screw is probably related to the incompletely screw head locked in the threaded chamber of the plate. Therefore, the use of bicortical screws should be preferred even using locking systems, especially in anatomical regions subjected to a higher concentration of load, as near the sniffle joint. In addition, it is concluded that the locking plate may be a viable option for the treatment of long bone fractures in wild animals, in particular femoral fractures of specimens of black capuchin monkey (Sapajus nigritus).
\end{abstract}

Keywords: wild animals, internal fixation, fracture. 


\section{INTRODUCTION}

The black capuchin monkey (Sapajus nigritus) belongs to the Order Primates, Family Cebidae, and it is as endemic species from Brazil [4]. The presence of these animals in transition areas between the wild and urban environments exposes them to trauma of different etiologies, such as road traffic accidents $[4,8]$.

Such trauma can result in orthopedic injuries, as long bones fractures, which may require surgical repair. Different orthopedic techniques have been described for fractures fixation in wild animals, based on the peculiarities of each species [8]. In addition, most surgical techniques currently pursue biological approaches with minimal lesion to the soft tissue, in order to promote faster bone consolidation with lower risk of complications, especially in those wild animals to be reintroduced to the nature [8].

In this context, the use of locking plates offers the benefit of limiting the contact between the implant and the bone, and consequently minimizing the vascular injury to the bone [12]. The locking plates also promote great angular stability to the fractures, especially complex fractures located in long bones with great muscular coverage, such as the femur and the humerus [12], since the screw head is locked in the locking plate with a locknut by screwing in a threaded chamber in the plate [5].

The aim this report is to describe the case of a black capuchin monkey (Sapajus nigritus), presented due to a femoral fracture, submitted to internal fixation using locking plate, and with satisfactory postoperative follow-up, characterized by complete bone consolidation of the femur and full recovery of the locomotor function of the hind limb.

\section{CASE}

An exemplar of an adult male black capuchin monkey (Sapajus nigritus) with $4.2 \mathrm{~kg}$ of body weight was presented due to history of functional impotence of the left hind limb.

At the physical and orthopedic examinations, using chemical restraint with $0.3 \mathrm{mg} \mathrm{kg}^{-1}$ of midazolam (Dormonid $\left.^{\circledR}\right)^{1}$ and $10 \mathrm{mg} \mathrm{kg}^{-1}$ of ketamine $\left(\text { Dopalen }^{\circledR}\right)^{2}$, both intramuscularly, were verified absence of the continuity of the bone and crepitus on the middle shaft of the left femur. All other clinical parameters presented were within the normal range reported for the species.
Due to these findings, a radiographic examination was performed on the lateral and craniocaudal projections, which allowed the visualization of a comminuted, diaphyseal fracture of the left femur (Figure 1).

The animal was then submitted to internal fixation of the femoral fracture using a $2.0 \mathrm{~mm}$ locking plate with 11 holes (Focus Orthopedic Implants ${ }^{\circledR}$ ).

For the internal fixation, a craniolateral approach to the femur was performed, according to Piermattei et al. [14]. After the bone exposure and fracture reduction, the plate was contoured and positioned on the lateral surface of the bone. Four locking screws were inserted through both cortices in the proximal bone segment, while other three locking screws were inserted in the distal bone segment. Two of the distal locking screws were inserted through both bone cortices (bicortical screws), while one of them were inserted through only one bone cortical (monocortical screw). In addition, an interphragmentary screw was positioned in the distal bone segment (Figure 2).

Afterwards, the suture of the fasciae latae was performed with 3-0 poliglecaprone 25 in a simple continuous pattern, followed by the suture of the subcutaneous and skin with, respectively, 3-0 poliglecaprone 25 in a Cushing pattern, and 2-0 polyamide (nylon) in a single interrupted pattern.

At the immediate postoperative radiographic examination, it were visualized the presence of the plate on the lateral surface of the femur from the greater trochanter region to immediately proximal to the lateral femoral epicondyle, as well as a good reduction of the fracture and the alignment of the bone axis.

For the postoperative period, it were prescribed $5 \mathrm{mg} \mathrm{kg}^{-1}$ of enrofloxacin (Baytril $\left.^{\circledR} 5 \%\right)^{4}$, every $8 \mathrm{~h}$, intramuscularly, and $4 \mathrm{mg} \mathrm{kg}^{-1}$ of tramadol hydrochloride (Tramadol hydrochloride $50 \mathrm{mg} / \mathrm{mL})^{5}$, every $8 \mathrm{~h}$ associated to $25 \mathrm{mg} \mathrm{kg}^{-1}$ dipyrone (Analgex $\mathrm{V}^{\circledR} 0,5 \mathrm{~g}$ / $\mathrm{mL})^{6}$, every $8 \mathrm{~h}$, both by the subcutaneous route. In addition, it was performed a Robert Jones bandage, and the animal was kept restricted in a cage of $2 \mathrm{~m}$ wide $\mathrm{x} 2.5 \mathrm{~m}$ long x $1.5 \mathrm{~m}$ high.

The animal showed increased hind limb weight support at 5 days postoperatively. The complete functional recovery of the left hind limb, however, was verified at 30 days postoperatively. Despite this, it was visualized at the radiographic examination the implant failure, characterized by the partial release of the plate from the distal bone segment, and consequently the loss of bone alignment. 
Due to this, the animal was submitted to another surgical intervention. After the approach described earlier, the locking screws inserted in the distal bone segment were removed. Then, the fracture was reduced and the same locking plate was repositioned on the lateral surface of the bone. At this moment, all the distal locking screws were inserted through both bone cortices.

At immediate postoperative radiographic examination, it were visualized the presence of the plate on the lateral surface of the femur, as well as a good reduction of the fracture and the realignment of the bone axis. At the craniocaudal radiographic projection, however, it was visualized a discrete lateral deviation of the distal bone segment with an adjacent bone proliferation (Figure 3).

For the second postoperative period, it were prescribed the same drugs administered at the previous postoperative period. In addition, a Robert Jones bandage was again performed, and the animal was kept restricted in the same previous cage for 26 days.

The animal showed hind limb weight support at the second day postoperatively. The complete functional recovery of the left hind limb, however, was achieved at 26 days postoperatively. In this moment, it was performed a new radiographic examination, which allowed the visualization of bone consolidation.

Due to the clinical and radiographic findings, the animal was reintroduced into its natural habitat.

\section{DISCUSSION}

The choice of the bone plate may play a fundamental role in the bone healing process [3]. Among many bone plates configuration, locking plates are highlighted, as they offer greater angular stability to the fracture when compared to the dynamic plates or the low contact dynamic plates [2] due to locknut by screwing in a threaded chamber of the plate $[7,11]$.

Additionally, the locking plates do not require close contact between the plate and the bone, which eliminate the need for the contouring of the plate to the bone [7], and consequently result in less injuring periosteum and blood vessels $[1,6]$. Regarding the treatment of fractures in wild animals, the possibility of a less precise contour of the plate is also a great advantage of the locking plates due to the lack of anatomical description of the bones in several species.

The low contact between the plate and the bone favours, therefore, the positioning of these implants in

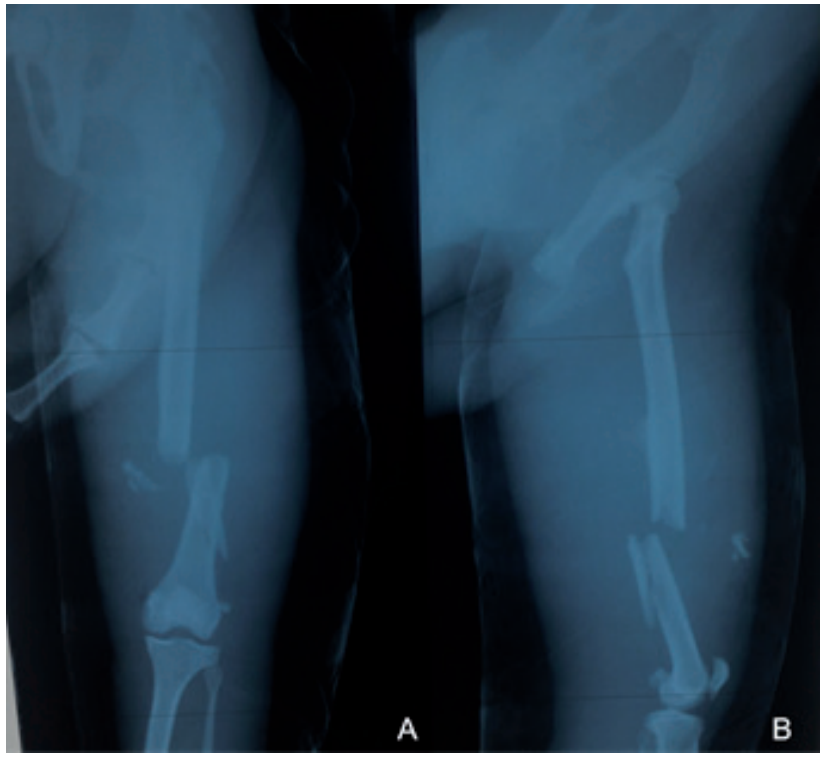

Figure 1. Radiographic examination of a black capuchin monkey (Sapajus nigritus). A- The craniocaudal projection shows a comminuted fracture in the distal shaft of the left femur. B- The lateral projection shows the presence of two bone fragments near the focus of the fracture.

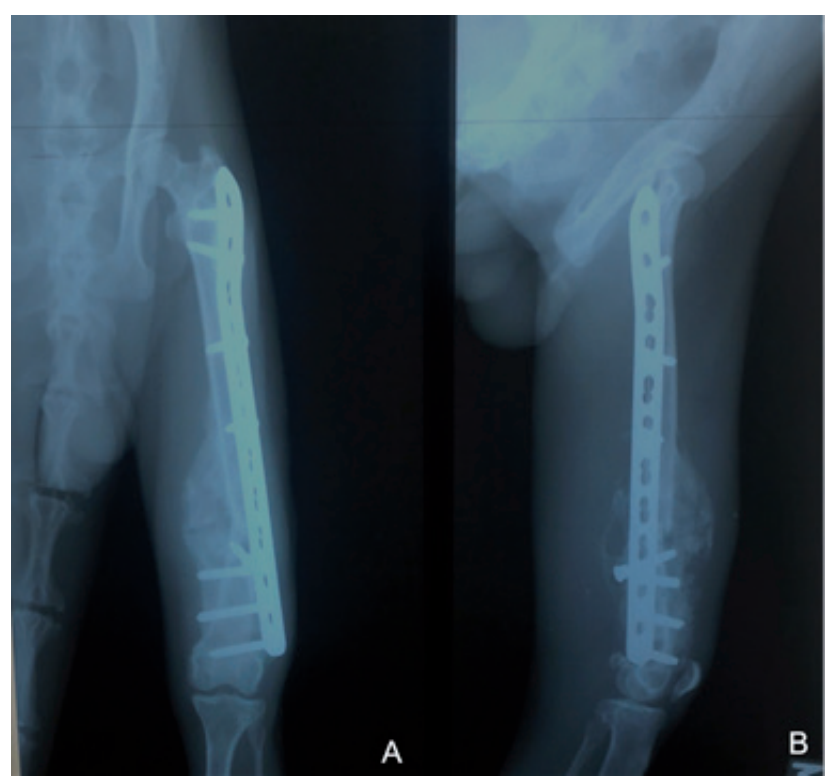

Figure 2. Immediate postoperative radiographic examination of a black capuchin monkey (Sapajus nigritus). A- The craniocaudal projection shows the alignment of the bone axis and the presence of the plate on the lateral surface of the femur. B- The lateral projection shows bone axis alignment and the presence of an interfragmentary screw in the segment distal of the fracture.

wild animals. In the present case, the locking plate was positioned on the lateral surface of the femur without difficulties or the need for additional bone intervention, such as ostectomies.

The aforementioned advantages of the locking plates allow a shorter time for bone healing compared to other conventional methods for internal fixation $[6,9]$, which is an important aspect to be considered for the treatment of fractures in wild animals to be reintroduced into nature. 


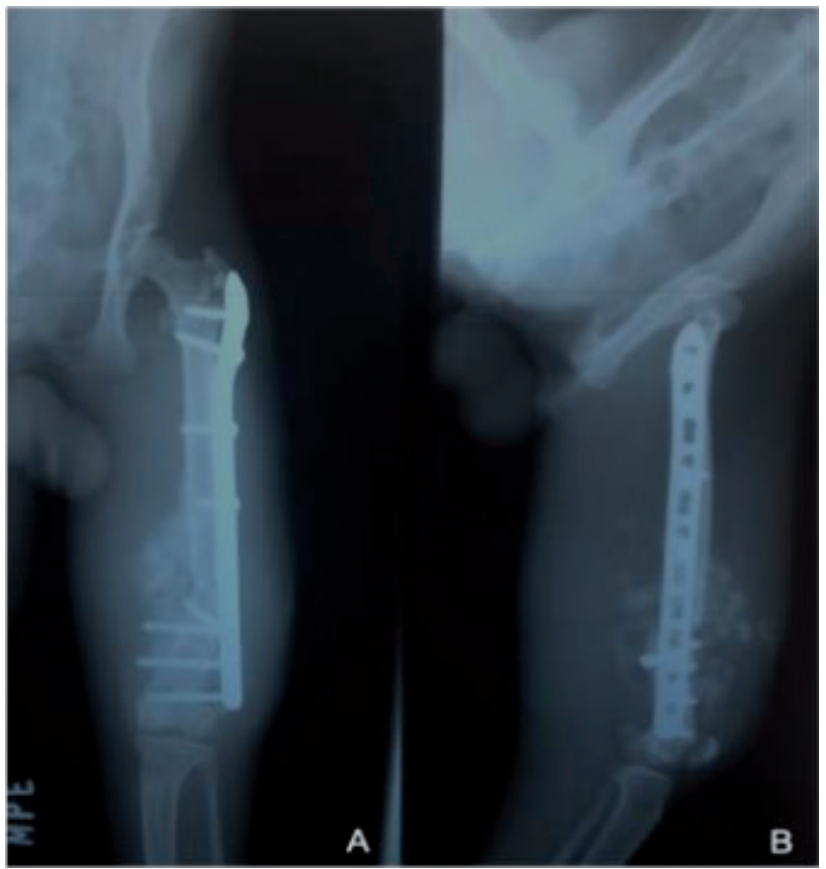

Figure 3. Second immediate postoperative radiographic examination of a black capuchin monkey (Sapajus nigritus). A- The craniocaudal projection shows a discrete lateral deviation of the distal shaft of the left femur. B- The lateral projection shows a great bone callus, and the maintenance of the positioning of the metallic implants.

The locking plates also promote rigid internal fixation and dispense the need of external implants, as external skeletal fixators, in several clinical situations, even as in exposed fractures or in the presence of osteomyelitis [15]. In addition, external skeletal fixators are not easy to handle in wild animals and its use is related to numerous postoperative complications due to the behavior of the wild animals [1]. In comparison, the rate of complications with the use of locking plates in fractures can be minimal [13].

Despite the low rate of complications with the use of locking plates, in the present case, it was visualized the partial release of the plate from the distal bone segment, which is probably related to the higher concentration of load near the sniffle joint and the early release of one monocortical screw, inserted in the distal bone segment [15].

The use of monocortical screws is permissible when using the locking system, since it has a monobloc effect in which all screws, when properly locked in the threaded chambers of the plate, are forced at the same time and therefore resist the pulling force [5].

In the present case, however, it is believed that the early release of the distal monocortical screw is probably related to the incompletely screw head locked in the threaded chamber of the plate. The implant failure resulted in a single point of fixation to the bone with consequent lower rolling resistance and weakening of the fracture stability $[10,12]$.

Therefore, the use of bicortical screws should be preferred even using locking systems, especially in anatomical regions subjected to a higher concentration of load, as near the sniffle joint. In addition, despite this complication, it is concluded that the locking plate may be a viable option for the treatment of long bone fractures in wild animals, in particular femoral fractures of specimens of black capuchin monkey (Sapajus nigritus). Additional studies with larger sample numbers, however, are necessary for the verification of the real applicability of the locking system in the species.

\section{MANUFACTURERS}

${ }^{1}$ Roche Diagnóstica Brasil. São Paulo, SP, Brazil.

${ }^{2}$ Ceva Saúde Animal Ltda. Paulínia, SP, Brazil.

${ }^{3}$ Focus Orthopedic Implants. Indaiatuba, SP, Brazil.

${ }^{4}$ Bayer Brasil. Belford Roxo, RJ, Brazil.

${ }^{5}$ Teuto S/A Laboratory. Anápolis, GO, Brazil.

${ }^{6}$ Agener União. São Paulo, SP, Brazil.

Acknowledgments. To PhD, MSc, DVM Halim Atique Netto by the financial and structural support to all the procedures performed in the reported case.

Declaration of interest. The authors report no conflicts of interest. The authors alone are responsible for the content and writing of the paper. 


\section{REFERENCES}

1 Beale B.S. \& Mccally R. 2012. Minimally invasive plate osteosynthesis: tibia and fíbula. Veterinary Clinics of North America: Small Animal Practice. 42: 1023-1044.

2 Carvalho A.V., Silva G.F., Meneghesso P.P., Gonçalves A.L.S., Lins B.T. \& Selmi A.L. 2010. Osteossíntese por placa óssea bloqueada em cães e gatos: relato de 23 casos. Jornal Brasileiro de Ciência Animal. 3(6): 172-173.

3 Chao P., Lewis D.D., Kowaleski M.P. \& Pozzi A. 2012. Biomechanical concepts applicable to minimally invasive fracture repair in small animals. Veterinary Clinics of North America: Small Animal Practice. 42: 853-872.

4 Cherem J.J., Kammers M., Ghizoni Jr. I.R. \& Martins A. 2007. Mamíferos de médio e grande porte atropelados em rodovias do Estado de Santa Catarina, Sul do Brasil. Revista Biotemas. 20(2): 81-96.

5 Cronier P., Pietu G., Dujardin C., Bigorre N., Ducellier F. \& Gerard R. 2010. The concept of locking plates. Orthopaedics \& Traumatology: Surgery \& Research. 96: 17S-36S.

6 Farouk O., Krettek C., Miclau T., Schandelmaier P., Guy P. \& Tscherne H. 1998. Effects of percutaneous and conventional plating techiniques on the blood supply to the femur. Archives of Orthopaedic and Trauma Surgery. 117: 438-441.

7 Ferrigno C.R.A., Cunha O., Caquias D.F.I., Ito K.C., Della Nina M.I., Mariani T.C. \& Ferraz V.C.M. 2011. Resultados clínicos e radiográficos de placas ósseas bloqueadas em 13 casos. Brazilian Journal of Veterinary Research and Animal Science. 48(6): 512-518.

8 Fischer W.A. 1997. Efeitos da BR-262 na mortalidade de vertebrados silvestres: síntese naturalística para a conservação da região do Pantanal, MS. 44p. Campo Grande, MS. Dissertação (Mestrado em Ecologia e Conservação) - Universidade Federal de Mato Grosso do Sul.

9 Halland P.J., Sjostrom L., Devor M. \& Haung A. 2009. Appendicular fractura repair in dogs using the locking compression plate system: 47 cases. Veterinary and Comparative Orthopaedics and Traumatology. 22: 309-315.

10 Kääb M.J., Frenk A., Schmeling A., Schaser K., Schütz M. \& Hass N.P. 2004. Locked internal fixator: sensitivity of screw/plate stability to the correct insertion angle of the screw. Journal Orthopaedics Trauma. 18(8): 483-487.

11 Koch D. 2005. Implants: Description and application. In: Johnson A.L., Houlton J.E.F. \& Vannini R. (Eds). AO Principles of Fracture Management in the Dog and Cat. New York: Thieme, pp.27-71.

12 Miller D.L. \& Goswami T. 2007. A review of locking compression plate biomechanics and their advantages as internal fixators in fracture healing. Clinical Biomechanics. 22: 1049-1062.

13 Oh C., Kim J., Byun Y., Oh J., Kim J., Kim S., Park B. \& Lee H. 2009. Minimally invasive plate osteosynthesis of subtrochanteric femur fractures with a locking plate: a prospective series of 20 fractures. Archives of Orthopaedic and Trauma Surgery. 129(12): 1659-1665.

14 Piermattei D., Flo G. \& Decamp C. 2006. Fractures of the Femur and Patella. In: Piermattei D., Flo G. \& Decamp C. (Eds). Handbook of Small Animal Orthopedics and Fracture Repair. 4th edn. St. Louis: Elsevier Saunders, pp.512-561.

15 Wagner M. 2003. General principles for the clinical use of the LCP. Injury. 34(2): 31-42. 